\section{Seven months on}

Alastair Hay updates developments since the Seveso disaster in northern Italy last year

Seven months after the explosion in the trichlorophenol reacitor at Seveso which resulted in the release of tetrachlorodibenzo- $p$-dioxin (dioxin), more details of its consequences are becoming apparent. The large number of organisations involved in assessing damage and formulating policy for decontamination of the area has prevented a crash programme. There has, however, been considerable agreement as to a general plan of action-a 'cleanup' operation to try to remedy damage, the full extent of which is still unknown.

According to $\mathrm{Mr}$ Alex Rice of Cremer and Warner-the British firm of consulting chemical engineers acting as 'technical auditors' of the decontamination programme-the work of removing dioxin

"is proceeding, and there will be a high degree of reclamation of property and land in a reasonable period of time. The nature of the discharge of the reactor contents resulted in a differential degree of dioxin contamination in different areas. It has been necessary, therefore, to arrive at a graded response to solve the problem of decontamination.

At the moment, in the most severely contaminated area designated as 'Zone $A^{\prime}$, hard surfaces are being cleaned and it is hoped that some $80 \%$ of the residents evacuated from the area will be able to return to their homes in a few months. Meanwhile, in 'Zone B', less severely affected by dioxin and where inhabitants have been able to remain in their homes, vegetation in certain selected areas is being cut down and incinerated".

From the evidence available at Seveso, Cremer \& Wanner estimate that $2.5-3 \mathrm{~kg}$ of dioxin was released in the reactor discharge. On this basis and through information obtained from a model simulating the explosive reaction at the ICMESA chemical plant, they suggest that only a few hundred grams of dioxin was actually deposited on vegetation and oiher surfiaces. They maintain that the majority of dioxin was too finelly dispersed and in a particulate form too small to permit precipitation to occur, with the result that thermal air currents cannied the matenial high into the atmosphere. Conditions on the day of the explosion were ideal for the photochemical decomposition of dioxin at these altitudes, but there is no evidence to substantiate that such a degradative process actually occurred.

Earlier reports suggested that the dioxin was percolating through the soil at Seveso more quickly than recorded on previous occasions in different localities. More necent investigations, however, confirm that $98 \%$ of the dioxin is strongly adsorbed on the top $4 \mathrm{~cm}$ of soil. Some of the methods of soil sampling in the earlier stages of the decontamination programme were not rigorous enough to exclude contamination of lower layers by material on the soil surface. The later investigations confirm previous reports in the literature that dioxin is relatively immobile in soirl.

The question of the teratogenic propenties of dioxin is still causing considerable anxiety to women in Seveso. The Lombardy regional government ruled last August that pregnant women from the contaminated zones around Seveso could have legal abortions, but local doctors have in many instances consistentily refused to terminate pregnancies, and only a small proportion of pregnant women from Seveso have had abortions in Italy. The foetuses from these women are currently being examined for any signs of abnormalities and the results of the investigations should be available by March.

The reluctance of the Italian doctors to perform abontions has forced many Seveso women to seek a termination in other countries. It is doubtful whether any of the foetuses from these abontions will be examined for malformations. Doctors in Britain have voiced their concern over this loss of potentially valuable information on human teratology. They argue that there should be some agreed international code of practice on the matter to prevent it recurring and add that in Britain in particular there are arrangements to facilitate abortions and examination of the aborted foetuses for signs of abnormalitties.

In the next few months women from Seveso who were in the first trimester of pregnancy in July last year will reach full term. The children born to them and to the mothers who conceived after the explosion are those most at risk from the teratogenic properties of dioxin. It is proving an agonising time for these mothers as no one can reassune them that their 'dioxin children', as they are known locally, will be unaffected. For them, as for all the people of Seveso, centain reassurances are impossible; it is just a matter of waiting. - A report in the Turin paper La Stampa this week says that many children at a school in the Seveso area are suffering from skin rashes.
IN BRIEF

\section{European energy policy moves}

Several important aspects of European energy policy were discussed in talks in London last week between $\mathrm{Mr}$ Anthony Wedgwood Benn, the UK Energy Minister, and his West German and Dutch counterparts. The meeting was part of a series Mr Benn is having as chairman of the EEC Council of Energy Ministers.

The ministers agreed that an early decision was needed on the question of increasing the uranium enrichment capacity of Urenco, the consortium established by the three countries which is facing problems because of Dutch concern about Germany's controversial nuclear deal with Brazil. The ministers also tacitly confirmed that the European Community fusion project, JET, was far from dead by agreeing that an early decision on its siting was needed.

No official comment was available from the UK Department of Energy on an appeal last week from the EEC Energy and Research Commissioner, Guido Brunner, who urged Britain to drop its opposition to a Euratom loans plan and its insistence on a minimum safeguard price for oil. These issues could become politically connected with the JET issue.

Brunner also appealed to the USA and Canada to maintain nuclear fuel supplies to the Community, and detailed the Community's efforts in reactor safety and nuclear export controls. A Community team of experts is shortly to visit Washington to discuss these matters.

\section{UK mercury report}

"Reassuring" is the word coming from the UK Department of the Environment (DoE) on the environmental impact of mercury in Britain. A report released last week (Environmental Mercury and Man, HMSO, £1.40) is the department's tenth pollution paper, and the product of an interdepartmental working group on heavy metals.

The average person in the UK, it says, is "at no discernible risk" from exposure to mercury, but for environmental and health reasons a comprehensive knowledge of the concentration and distribution of mercury must be developed and the toxicology of mercury understood. The report says more research is needed on both the conversion of mercury to and from methylmercury compounds and the environmental pathways of mercury across the water-sediment interface in the aquatic environment; research on the mechanisms of its toxic action and on low level exposure to it over long periods is also necessary. 


\section{Help for computer industry}

UK government plans to concentrate on electronics as part of its drive to boost exports were revealed last week. The proposal, part of the Labour government's overall 'industrial strategy', followed an announcement that the National Enterprise Board (NEB) is to become involved in the computer industry through a newly-created NEB subsidiary, INSAC Data Systems. The idea initially is to stem fragmentation in the software sector, and later to become involved in minicomputers and peripherals. The news coincides with the publication of details of a consultant's report on the European computer industry which forecasts a bleak outlook for microelectronics in the absence of a radical restructuring of the industry.

\section{New genetics draft}

The consultative document drawn up by the UK Health and Safety Commission (HSC) last August containing drafit regulations for the control of genetic manipulation experiments in Britain is thought to be still under discussion with the principal scientific interests concerned.

A report appeared last week stating that the HSC's controversial allembracing clause, requiring notification from any person carrying on "any activity intended to alter, or likely to alter" the genetic constitution of any microorganism, has now been rewritten. The new notification clause which, it was said, the HSC intended to put in its place, reads:

"No person shall carry on any activity which, by using biochemical manipulation of extra-cellular nucleic acids, is intended or likely.

(a) to insert genetic information into organisms, and

(b) to circumvent the natural barriers to such insertions, and

(c) to propagate that information, unless notice has been given ..."

This proposal, which went out before Christmas, was a new draft for comment, and does not necessarily represent the HSC's final proposed definition of genetic manipulation experiments.

\section{Mediterranean discussions}

Representatives from fifteen of the $\mathbf{1 8}$ nations surrounding the Mediterranean met last week in Split, Yugoslavia, to discuss proposals for combating pollution of the sea they all share. They meet again in Athens this week.
THE production of food is bound to overshadow many other human activities increasingly in years to come. Scientific agriculture is currently beset with many problems and wouldbe interveners. A trend in recent years has been to take away the authority of agriculturists over the methods used in agricultural production. The excuse seems to be that those who till the soil cannot be trusted either to 'protect the environment' or to produce food that is sufficiently free from 'contamination' to satisfy the ideals of consumerists.

An inevitable result of these bureaucratic machinations is an increase in the cost of producing food. The advent of a new administration in Washington has given rise to gleeful anticipation of more power by those who oppose many of the technological practices used in agriculture. Such opposition will increase the cost of food production further.

The success of scientific agriculture has made groceries so cheap and plentiful in the USA that the food supply is taken for granted. This may be attributable to the fact that food is so easily obtained that it has lost its aura of being a treasured gift of beneficent Mother Nature. The urban population, now two generations removed from farm life, knows very little about food production. As a result, consumerists, defined as individuals who are quite certain of what is best for the interests of consumerists, hold sway increasingly over consumers, who are apparently somewhat bewildered by it all.

For example, the successful campaign to cast out Red Dye No. 4 from maraschino cherries was based upon the finding that the dye produced tumours in laboratory rodents, and a grateful populace should have thrown the deadly preserved fruit into the garbage. However, we learn that in the supermarkets there was a run on red maraschino cherries by

\section{Agriculture 1977}

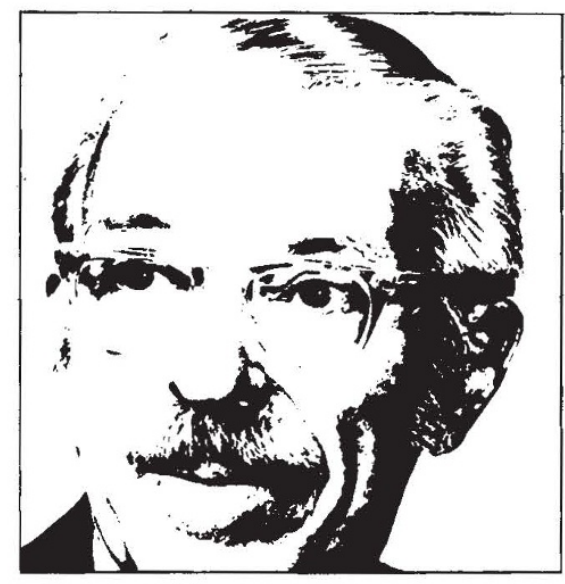

\section{THOMAS H. JUKES}

hoarders who feared an impending ban.

Consumerists seem not to realise or acknowledge the basic facts of agriculture and nutrition. Some of these are that food contains substances that are toxic at high levels but are sufficiently harmless in the amounts actually present that they offer no finite hazard to health. Such substances include pesticide residues as well as other adventitious contaminants. Food can be produced without such residues, or it may in some instances be refined to remove them, as in the case of sugar.
But such finickiness, carried out to quieten the apprehensions of an opulent minority, do not fit the pattern of making an effort towards achieving abundance and low cost of food in the face of a rapidlyincreasing requirement by a burgeoning global population. A few months ago, there was an uproar by consumerists over the FDA tolerances for 'filth' in foods. This was a great source of amusement to anyone who had worked on a farm, and who knew, as a fact of life, that grain and rats are constant companions. Indeed, some accident of design has made rat faeces the size and shape of wheat kernels, and hence the two items are virtually inseparable by the usual screening processes. Canned vegetables and tomatoes have always contained insect parts, more so in prepesticide days.

A misapprehension in some quarters is that food of plant origin is somehow 'purer', 'closer to Mother Earth', and 'more healthy' than food derived from animal products. Actually, toxicants, including oestrogens, goitrogens, alkaloids, and fungal carcinogens, occur naturally far more often in plant foods than in animals. Domestic animals, serving as sources of meat, milk and eggs, can serve as 'filters' to metabolise and remove such substances, or to reduce their levels in the human diet. Cereal grains, of course, will continue to be the prime source of calories for human beings throughout the world. The business of feeding people must go on apace, and, to this end, let us hope that the 'Washington consumerist crowd' will not be given the opportunity to pour any more gravel in the gears that they introduced in 1976. 